\title{
Socioeconomic and demographic determinants of birth weight in southern rural Ghana: evidence from Dodowa Health and Demographic Surveillance System
}

Alfred Kwesi Manyeh ${ }^{1 *}$, Vida Kukula1,3, Gabriel Odonkor ${ }^{1}$, Rosemond Akepene Ekey ${ }^{2,3}$, Alexander Adjei ${ }^{1,2,3}$, Solomon Narh-Bana ${ }^{1,3}$, David Etsey Akpakli, ${ }^{1,3}$ and Margaret Gyapong ${ }^{1,3}$

\begin{abstract}
Background: Low birth weight (LBW) is one of the major factors affecting child morbidity and mortality worldwide. It also results in substantial costs to the health sector and imposes a significant burden on the society as a whole. This study seeks to investigate the determinants of low birth weight and the incidence of LBW in southern rural Ghana.

Methods: Pregnancy, birth, demographic and socioeconomic information of 6777 mothers who gave birth in 2011, 2012, and 2013 and information on their babies were extracted from a database. The database of Dodowa Health and Demographic Surveillance System is a longitudinal follow-up of over 24,000 households. The incidence of LBW was calculated and the univariable and multivariable associations between exposure variables and outcome were explored using logistic regression. STATA 11 was used for the analyses.

Result: The results revealed that $40.21 \%$ of the infants were not weighed at birth and the incidence of LBW for 2011 to 2013 was 8.72, 7.04 and $7.52 \%$ respectively. Women aged 20-24, 25-29, 30-34 years were more than twice more likely to have babies weighing $\geq 2.5 \mathrm{~kg}$ compared to those $<20$ years (OR:2.32, 95 \% Cl:1.65-3.26, OR:2.73, 95 \% Cl: 1.96-3.79, OR:2.87, $95 \% \mathrm{Cl}: 2.06-4.01)$ and mothers who were $>34$ years were more than three times more likely to have babies weighed $\geq 2.5 \mathrm{~kg}$ (OR: $3.59,95 \% \mathrm{Cl}: 2.56-5.04$ ). Mothers who were civil servants were $77 \%$ more likely to have babies weighed $\geq 2.5 \mathrm{~kg}$ (OR: 1.77, $95 \% \mathrm{Cl}: 1.99-2.87$ ) compared to those who were unemployed. After adjusting for other explanation variables, mothers from poorer households were $30 \%$ more likely to have babies who weighed $\geq 2.5 \mathrm{~kg}$ (OR: $1.30,95 \% \mathrm{Cl}: 1.01-1.66)$ compared to those from the poorest households. Women with parity2 and parity $>3$ were $30 \%$ and $81 \%$ more likely to have babies weighing $\geq 2.5 \mathrm{~kg}$ (OR: 1.30, $95 \%$ Cl: 1.03-1.63, OR: 1.81, $95 \%$ Cl: $1.38-2.35)$ compared to those with parity 1 . Male infants were $52 \%$ more likely to weigh $\geq 2.5 \mathrm{~kg}$ at birth (OR: 1.52 , $95 \%$ Cl: 1.32-1.76) compared to females.
\end{abstract}

Conclusion: Our study revealed that having infant birth weight $\geq 2.5 \mathrm{~kg}$ is highly associated with socioeconomic status of women household, the gender of an infant, parity, occupation and maternal age.

Keywords: Birth weight, Socioeconomic, Determinants, Health and demographic surveillance system, Dodowa, Ghana

\footnotetext{
* Correspondence: alfredmanyeh4u@gmail.com

'Dodowa Health Research Centre, P. O. Box. DD1, Dodowa, Ghana

Full list of author information is available at the end of the article
} 


\section{Background}

Low birth weight (LBW) is a major public health problem worldwide especially in low and middle income countries. It is a major determinant of mortality, morbidity and disability in neonatal, infancy and childhood and has a long term impact on health outcomes in adult life. Low birth weight results in substantial costs to the health sector and imposes a significant burden the society as a whole [1].

LBW is considered the single most important predictor of infant death within the first month of delivery $[2,3]$ and together with preterm births, they are indicators of potential lifelong consequences to individuals, families, and communities at large. Birth weight is a good indicator of the reproductive and general health status of a population. It is not only about the baby's health and nutritional status but also the physical and psychosocial growth and development of babies and their chances of survival [2-4].

The Centre for Disease and Control (CDC) classified birth weight as extremely low birth weight (ELBW) in infants whose birth weight was below $1 \mathrm{~kg}$, very low birth weight (VLBW) in infants whose birth weight was below $1.5 \mathrm{~kg}$, low birth weight (LBW) in infants whose birth weight was below $2.5 \mathrm{~kg}$, normal birth weight (NBW) in infants whose birth weight was below $4 \mathrm{~kg}$, and high birth weight (HBW) in infants whose birth weight was more than $4 \mathrm{~kg}$ Health risk depends on these classifications [5]. It was a goal of the 2012 World Health Assembly to reduce the number of infants born weighing below $2.5 \mathrm{~kg}$ by $30 \%$ by the year 2025 . This would translate into a $3 \%$ relative reduction per year between 2012 and 2025 and a reduction from approximately 20 million to 14 million infants with low weight at birth [6]. The prevalence of LBW is estimated to be $15 \%$ worldwide with a range of $3.3-38 \%$ and occurs mostly in low and middle income countries [1] representing more than 20 million of all births per year. The prevalence is highest in South-Central Asia and subSaharan Africa, but there are intra-country variations. It is a global concern, as some developed countries such as Spain, Great Britain, Northern Ireland and the United States of America are also faced with high rates for their contexts [7].

Factors associated with birth weight operate broadly through genetic, socio-demographic and environmental channels. These factors include the sex of the child for the same gestational age [8]; maternal age $[9,10]$; maternal birth weight [11] and maternal weight [1, 12-15]. Others include maternal nutrition - cumulatively, and during pregnancy $[16,17]$; smoking $[1,18]$; type of cooking fuel [19-22]; and socioeconomic status [23, 24]. While LBW in the developing world stems primarily from the mother's poor health and nutrition, cigarette smoking during pregnancy is the leading cause of LBW in the developed world. In both developed and developing countries alike, LBW is most frequently associated with teenagers who give birth when their own bodies have not yet fully developed [25].. Studies show that in sub-Saharan Africa and other developing parts of the world, poverty, low education, late initiation of obstetric care, poor nutrition, and micronutrient supplementation during pregnancy are associated with LBW [17, 26-29]. Parity and birth intervals are also risk factors [30-35].

The Ghana Multiple Indicator Cluster Survey (MICS) found a LBW prevalence of $9.1 \%$ and $11 \%$ in 2006 and 2011 respectively $[4,36]$. However, in 2006 only two in five babies were weighed at birth. The report shows that $54 \%$ of infants were weighed at birth [4] with regional variations from as high as $85 \%$ in Greater Accra region and as low as $25 \%$ in the Northern region. Also, children from rural households and those from the poorest households are less likely than the more advantaged children to be weighed at birth [4]. Additionally, the possibility that children are weighed at birth increased with an increase in the mother's level of education [4]. Another study in 2009 revealed that approximately $10 \%$ of all births in Ghana were LBW [36]. Studying the socioeconomic and demographic determinants of birth weight is important for both public health and clinical perspectives since such information would be crucial in understanding the effect of demographic variables and changes in socioeconomic status of people on the birth weight of infants. In Ghana, no study has been done using longitudinal population-based data to assess the socioeconomic and demographic determinants of birth weight. This study sought to investigate the determinants of birth weight and the incidence of LBW in southern rural Ghana using population-based longitudinal data.

\section{Methods \\ Study area}

Data for this study were extracted from the Dodowa Health and Demographic Surveillance System (DHDSS) site database. The DHDSS is located in the southeastern part of Ghana and operates within the boundaries of the Shai-Osudoku and Ningo-Prampram districts [37]. The DHDSS site lies between latitude $5^{\circ} 45^{\prime}$ south and $6^{\circ} 05^{\prime}$ north and longitude $0^{\circ} 05^{\prime}$ east and $0^{\circ} 20^{\prime}$ west with a land area of $1528.9 \mathrm{~km}^{2}$. It is about $41 \mathrm{~km}$ from the national capital, Accra [37, 38]. The two districts are made up of a population of 115,754 people in 380 communities. There are 23,647 households living in a total land area of $1442 \mathrm{~km}^{2}$. The inhabitants are predominantly subsistence farmers, fishermen and petty traders [38]. Road networks in the DHDSS are usually 
inaccessible during the wet seasons, making access to health and other services a challenge.

The DHDSS visits every household in the demographic surveillance area twice in a year to collect data on demographic, migration and other health indicators [38]. Health care services in the DHDSS are delivered by hospitals, health centres, CHPS zones, private facilities, clinics, maternity homes, mission clinics and quasi government clinics.

\section{Study population and sample}

The study population is made up of all babies born to resident women in the DHDSS and the study sample comprised 6777 babies born to women who were resident in the DHDSS from 1st January 2011 to 31st December 2013. All babies born to women who were not resident members of the DHDSS and those born outside the study period were excluded.

\section{Outcome and exposure variables}

The outcome variable for this study is birth weight which is binary recorded as: 1 "Birth Weigh $<2.5 \mathrm{~kg}$ " and 0"Birth Weight $\geq 2.5 \mathrm{~kg}$ ". From the available data, eleven exposure variables were selected based on biological plausibility, the available literature and the potential to influence birth weight. These exposure variables include: infant's gender, maternal age, maternal education, maternal occupation, parity and the intake of Intermittent Preventive Treatment (IPTp) for prevention of malaria in pregnancy. Others include whether this is the mothers first live birth or not, her marital status, antenatal (ANC) attendance, type of cooking fuel, and the wealth index.

The wealth index (socioeconomic status) is a proxy measure of a household's long term standard of living; it is based on social status, asset ownership, and availability of utilities, among others. The index measures were combined into a wealth index, using weights derived through principal component analysis (PCA) [39]. The proxies from the PCA were divided into five quintiles; poorest, very poor, poor, less poor and least poor. Maternal ages at delivery were calculated using the mothers' and babies' birthdates.

\section{Measurement and statistical analysis}

The study used secondary data from the DHDSS. Birth weight variable which was captured from the health record book of the child during the DHDSS data collection period and exposure variables were extracted from the database of DHDSS. The associations between each exposure variable and birth weight were explored at the univariable level and those significant at $p<0.05$ were entered together into a multiple logistic regression model.
To ensure the assumption of independence of observations, all multiple births were excluded and assessment of clustering at household level was carried out and the assumption of independence was upheld. Collinearity between all variables and models fit with and without adjustment were checked using Pearson's correlation matrix.

All analyses were conducted in Stata version 11 and results were presented in the form of tables and summary statistics in odds ratios (OR), with $95 \%$ confidence intervals $(\mathrm{CI})$ and $\mathrm{p}$-values.

\section{Results}

\section{Background characteristics}

Tables 1 and 2 provide the descriptive information on the demographic and socioeconomic characteristics of 6777 mothers whose babies were included in the study. The average age of the mothers is 28 years with a standard deviation of \pm 7 . The majority of the mothers $(73.03 \%)$ were of the Ga-Dangme ethnic group and 91.34 \% were Christians. While petty trading was stipulated as the profession for $30.18 \%$ of the women whose babies were studied, $22.86 \%$ were unemployed. Farmers, students, and artisans formed 17.12, 13.89 and $12.42 \%$ of the respondents respectively. Other categories of occupation contributed smaller proportions. While a significant proportion of the mothers (34.59\%) were educated up to junior high level, about $30 \%$ of them had primary education and $26.83 \%$ had no education. Only $8.20 \%$ of the mothers detailed senior high school level of education and above as their level of education. About half of the mothers $(49.75 \%)$ described their marital status as cohabiting, $28.28 \%$ were single, $20.04 \%$ were married and $1.95 \%$ were divorced/separated. Of the women whose babies were studied, $29.82 \%$ had parity of more than three, $26.59 \%$ had parity of one, $24.64 \%$ had parity of two and $18.95 \%$ had parity of three. Most of the women (49.23\%) used charcoal as cooking fuel and $41.64 \%$ used wood. Liquefied petroleum gas (LPG) contributed to only $8.84 \%$ of the cooking fuel. Majority of the mothers $(91.12 \%)$ received IPTp during their pregnancy and $81.38 \%$ had at least four ANC visits during pregnancy. More than half of the babies born during the study period were male $(52.24 \%)$. While $40.21 \%$ of the babies born during the study period were not weighed, $55.05 \%$ weighed $\geq 2.5 \mathrm{~kg}$ and $4.74 \%$ weighed $<2.5 \mathrm{~kg}$. The results revealed that the incidence of LBW between 2011 and 2013 is $8.72,7.04$ and $7.52 \%$ respectively.

\section{Univariable and multivariable analysis}

The association between the dependent and independent variables is shown in Table 3. Increasing maternal age was significantly associated with the likelihood of a mother giving birth to a baby that weighed $\geq 2.5 \mathrm{~kg}$. Women aged 
Table 1 Socio-demographic characteristics of the study participants

\begin{tabular}{lll}
\hline Characteristics & Frequency $^{\text {a }}$ & Proportion (\%) \\
\hline Age group & & \\
$<20$ & 769 & 11.35 \\
$20-24$ & 1592 & 23.49 \\
$25-29$ & 1841 & 27.17 \\
$30-34$ & 1411 & 20.82 \\
$34+$ & 1164 & 17.18 \\
Mean=27.83 (SD =6.97) & & \\
Ethnicity & & \\
Ga-Dangme & 4949 & 73.03 \\
Akan & 357 & 5.27 \\
Ewe & 1054 & 15.55 \\
Northern & 363 & 5.36 \\
Others & 54 & 0.8
\end{tabular}

Religion

$\begin{array}{lll}\text { Christianity } & 6190 & 91.34 \\ \text { Islamic } & 411 & 6.06 \\ \text { Traditional } & 102 & 1.51 \\ \text { Others } & 74 & 1.05\end{array}$

Occupation

\begin{tabular}{|c|c|c|}
\hline Unemployed & 1549 & 22.86 \\
\hline Farmer & 1160 & 17.12 \\
\hline Artisan & 842 & 12.42 \\
\hline Trader & 2045 & 30.18 \\
\hline Civil Servant & 109 & 1.61 \\
\hline Student & 941 & 13.89 \\
\hline Others & 131 & 1.93 \\
\hline \multicolumn{3}{|l|}{ Level of education } \\
\hline No Education & 1818 & 26.83 \\
\hline Primary & 2055 & 30.32 \\
\hline Junior School Level & 2344 & 34.59 \\
\hline SHS and above & 556 & 8.20 \\
\hline Others & 4 & 0.06 \\
\hline \multicolumn{3}{|l|}{ Marital status } \\
\hline Single & 1888 & 28.28 \\
\hline Married & 1338 & 20.04 \\
\hline Separated/Divorced & 129 & 1.93 \\
\hline Cohabiting & 3321 & 49.75 \\
\hline \multicolumn{3}{|l|}{ Parity } \\
\hline Parity1 & 1802 & 26.59 \\
\hline Parity2 & 1670 & 24.64 \\
\hline Parity3 & 1284 & 18.95 \\
\hline Parity3+ & 2021 & 29.82 \\
\hline
\end{tabular}

Table 1 Socio-demographic characteristics of the study participants (Continued)

\begin{tabular}{lll}
\hline Socio economic status & & \\
Poorest & 1362 & 20.10 \\
Poorer & 1349 & 19.91 \\
Poor & 1356 & 20.01 \\
Less Poor & 1355 & 19.99 \\
Least Poor & 1355 & 19.99 \\
\hline$n=6777 ; S D=$ Standard Deviation ${ }^{2}$ number of respondents across some \\
categories may not add up to 6777 due to missing data
\end{tabular}

20-24, 25-29, 30-34 years were more than twice more likely to have babies who weighed $\geq 2.5 \mathrm{~kg}$ compared to those aged less than 20 years (OR:2.32, $95 \%$ CI:1.65-3.26, OR:2.73, 95 \% CI:1.96-3.79, OR:2.87, 95 \% CI:2.06-4.01). Mothers aged 30 years and above were more than three times more likely to have babies who weighed $\geq 2.5 \mathrm{~kg}$. After adjusting for occupation, parity, socioeconomic status and gender of infant, maternal age is still significantly associated with birth weight such that mothers who were 20 years and older were more than two times likely to have babies who weighed $\geq 2.5 \mathrm{~kg}$ compared to those aged $<20$ years.

Marital status, level of education, IPTp intake and number of ANC visits were not significantly associated with birth weight. Mothers who were farmers, artisans

Table 2 Socio-demographic characteristics of the study participants

\begin{tabular}{lll}
\hline Characteristics & Frequency $^{\text {a }}$ & Proportion (\%) \\
\hline Cooking fuel & 532 & 8.84 \\
Gas & 2964 & 49.23 \\
Charcoal & 2507 & 41.64 \\
Wood & 18 & 0.30 \\
Others & & \\
Have you received IPTp & 6157 & 91.12 \\
Yes & 600 & 8.88 \\
No & & \\
Number of ANC visits & 1249 & 18.62 \\
Less than four visit & 5460 & 81.38 \\
At least four visit & & \\
Infant's gender & 3237 & 47.76 \\
Female & 3540 & 52.24 \\
Male & & \\
Birth-weight & 321 & 4.74 \\
Birth weight $<2.5 \mathrm{~kg}$ & 3731 & 55.05 \\
Birth weight $\geq 2.5 \mathrm{~kg}$ & 2725 & 40.21 \\
Not weighed &
\end{tabular}

$n=6777 ; S D=$ Standard Deviation ${ }^{\text {a }}$ number of respondents across some categories may not add up to 6777 due to missing data 
Table 3 Crude and adjusted odd ratios of determinates of birth weight

\begin{tabular}{|c|c|c|c|c|}
\hline \multirow[b]{2}{*}{ Characteristics } & \multicolumn{2}{|c|}{ Crude } & \multicolumn{2}{|c|}{ Adjusted $^{b}$} \\
\hline & $\mathrm{OR}$ & $P$-values (95 \% Cl) & $\mathrm{OR}$ & $P$-value $(95 \% \mathrm{Cl})$ \\
\hline \multicolumn{5}{|l|}{ Age group } \\
\hline$<20$ & 1.00 & & 1.00 & \\
\hline $20-24$ & 2.32 & $<0.001(1.65-3.26)^{a}$ & 2.18 & $<0.001(1.53-3.10)^{a}$ \\
\hline $25-29$ & 2.73 & $<0.001(1.96-3.79)^{\mathrm{a}}$ & 2.34 & $<0.001(1.62-3.39)^{a}$ \\
\hline $30-34$ & 2.87 & $<0.001(2.06-4.01)^{\mathrm{a}}$ & 2.20 & $<0.001(1.48-3.28)^{a}$ \\
\hline $34+$ & 3.59 & $<0.001(2.56-5.04)^{\mathrm{a}}$ & 2.52 & $<0.001(1.67-3.82)^{a}$ \\
\hline \multicolumn{5}{|l|}{ Marital status } \\
\hline Single & 1.00 & & & \\
\hline Married & 1.16 & $0.157(0.94-1.14)$ & & \\
\hline Separated/Divorced & 0.89 & $0.690(0.51-1.55)$ & & \\
\hline Cohabiting & 1.14 & $0.141(0.92-1.55)$ & & \\
\hline \multicolumn{5}{|l|}{ Level of education } \\
\hline No Education & 1.00 & & & \\
\hline Primary & 0.92 & $0.451(0.75-1.14)$ & & \\
\hline Junior High School & 1.12 & $0.239(0.93-1.55)$ & & \\
\hline Senior High School \& above & 1.19 & $0.184(0.92-1.55)$ & & \\
\hline \multicolumn{5}{|l|}{ Occupation } \\
\hline Unemployed & 1.00 & & 1.00 & \\
\hline Farmer & 1.33 & $0.022(1.04-1.70)^{a}$ & 1.10 & $0.466(0.85-1.42)$ \\
\hline Artisan & 1.31 & $0.031(1.03-1.67)^{a}$ & 1.23 & $0.115(0.95-1.58)$ \\
\hline Trader & 1.23 & $0.050(1.00-1.50)$ & 1.04 & $0.687(0.84-1.29)$ \\
\hline Civil Servant & 1.82 & $0.012(1.14-2.90)^{a}$ & 1.77 & $0.021(1.09-2.87)^{a}$ \\
\hline Student & 0.92 & $0.554(0.71-1.20)$ & 1.31 & $0.068(0.98-1.74)$ \\
\hline Others & 1.40 & $0.197(0.84-2.35)$ & 1.43 & $0.184(0.84-2.41)$ \\
\hline \multicolumn{5}{|l|}{ Parity } \\
\hline Parity 1 & 1.00 & & 1.00 & \\
\hline Parity2 & 1.48 & $<0.001(1.20-1.83)^{a}$ & 1.30 & $0.026(1.03-1.63)^{a}$ \\
\hline Parity3 & 1.46 & $<0.001(1.16-1.82)^{a}$ & 1.23 & $0.116(0.95-1.59)$ \\
\hline Parity3+ & 2.12 & $<0.001(1.74-2.59)^{a}$ & 1.81 & $<0.001(1.38-2.35)^{a}$ \\
\hline \multicolumn{5}{|l|}{ Socio economic status } \\
\hline Poorest & 1.00 & & 1.00 & \\
\hline Poorer & 1.30 & $0.033(1.02-1.65)^{a}$ & 1.30 & $0.040(1.01-1.66)^{a}$ \\
\hline Poor & 1.03 & $0.795(0.81-1.31)$ & 1.03 & $0.796(0.81-1.32)$ \\
\hline Less Poor & 0.93 & $0.516(0.73-1.17)$ & 0.93 & $0.578(0.74-1.19)$ \\
\hline Least Poor & 1.27 & $0.033(1.02-1.58)^{a}$ & 1.24 & $0.064(0.99-1.55)$ \\
\hline \multicolumn{5}{|l|}{ Infant's gender } \\
\hline Female & 1.00 & & 1.00 & \\
\hline Male & 1.52 & $<0.001(1.32-1.76)^{a}$ & 1.56 & $<0.001(1.35-1.81)^{a}$ \\
\hline \multicolumn{5}{|l|}{ Have you receive IPTp } \\
\hline Yes & 1.00 & & & \\
\hline No & 1.15 & $0.333(0.87-1.52)$ & & \\
\hline
\end{tabular}


Table 3 Crude and adjusted odd ratios of determinates of birth weight (Continued)

\begin{tabular}{lll}
\hline Number of ANC visits & \\
Less than four visit & 1.00 & $0.206(0.92-1.44)$ \\
At least four visit & 1.15 & \\
Cooking fuel & & \\
Gas & 1.00 & $0.099(0.65-1.04)$ \\
Charcoal & 0.82 & $0.682(0.74-1.22)$ \\
Wood & 0.95 & $0.222(0.03-2.18)$ \\
Others & 0.28 & \\
\hline
\end{tabular}

OR Odd Ratio, ${ }^{\mathrm{a}}$ statistically significant. $\mathrm{Cl}$ Confidence Interval. ${ }^{\mathrm{b}}$ Correct classification rate of the model $=75.96 \%$

or civil servants were $33,31,82 \%$ respectively more likely to have babies who weighed $\geq 2.5 \mathrm{~kg}$ (OR:1.33, 95 \% CI:1.04-1.70, OR:1.31, 95 \% CI:1.03-1.67, OR:1.82, $95 \%$ CI:1.14-2.90) compared to unemployed mothers. After adjusting for parity, socioeconomic status and infant gender, civil servants were $77 \%$ more likely to have babies who weighed $\geq 2.5 \mathrm{~kg}$ (OR:1.77, $95 \% \mathrm{CI}: 1.99-2.87$ ) compared with those mothers who were unemployed.

While women with parity 2 and 3 were $48 \%$ and $46 \%$ more likely to have babies who weighed $\geq 2.5 \mathrm{~kg}$ respectively (OR: 1.48, 95 \% CI: 1.20-1.83, OR: 1.46, 95 \% CI: 1.16-1.82), those with parity higher than three were more than two times more likely to have babies weighing $\geq 2.5 \mathrm{~kg}$ (OR: 2.12, 95 \% CI: 1.74-2.59) compared to those with parity one. In the presence of other explanatory variables, women with parity two and more than three were $30 \%$ and $81 \%$ more likely to have babies weighing $\geq 2.5 \mathrm{~kg}$ respectively (OR:1.30, $95 \% \mathrm{CI}: 1.03-$ 1.63, OR:1.81, $95 \%$ CI:1.38-2.35) compared to those with parity one.

Mothers within the poorer socioeconomic status category were $30 \%$ more likely to have babies who weighed $\geq 2.5 \mathrm{~kg}$ (OR: 1.30, $95 \% \mathrm{CI}$ : 1.02-1.65) compared to those in the poorest category. Those women from least poor households were $27 \%$ more likely to have babies weighed $\geq 2.5 \mathrm{~kg}$ (OR: 1.27, $95 \% \mathrm{CI}$ : 1.02-1.58) compared to those from the poorest households. After adjusting for other explanation variables, mothers from poorer households were $30 \%$ more likely to have babies who weighed $\geq 2.5 \mathrm{~kg}$ (OR: 1.30, $95 \% \mathrm{CI}$ : 1.01-1.66).

Male infants were $52 \%$ more likely to weigh $\geq 2.5 \mathrm{~kg}$ at birth (OR: 1.52, $95 \% \mathrm{CI}: 1.32-1.76$ ) compared to females and this was statistically significant after adjusting for other explanatory variables (OR: 1.56, $95 \%$ CI: $1.35-1.81)$.

\section{Discussion}

This study sought to examine the determinants of birth weight and the incidence of LBW in southern rural Ghana using secondary data from DHDSS from 1st
January 2011 to 31st December 2013. The incidence of LBW in this population-based study is a little lower than that of Ghana MICS which found a LBW prevalence of $9.1 \%$ and $11 \%$ in 2006 and 2011 respectively $[4,36]$. Our study revealed that having infant birth weight $\geq 2.5 \mathrm{~kg}$ is highly associated with socioeconomic status of women household, gender of infant, parity, occupation and maternal age.

The findings show a strong association between birth weight and socioeconomic status which is consistent with other studies which showed that higher socioeconomic status reduced the risk of LBW [40-42]. This shows that poverty is an important determinant of birth weight as shown in other contexts [43-45]. Low birth weight could be due to poor maternal nutritional intake among mothers with lower socioeconomic status as found in other studies [46, 47].

The findings suggested that a mother's level of education is not associated with birth weight which is consistent with some studies which reported that birth weight is not statistically significant with maternal level of education $[48,49]$, it however contrasts the findings of other studies [50, 51] which found an association between birth weight and the mother's level of education.

The results of this study also indicate that the gender of infants is highly associated with birth weight, male infants are more likely to experience birth weight $\geq 2.5 \mathrm{~kg}$ than female infants. Similar findings have been reported in other studies [52-54].

The results also indicated that mothers aged below 20 years had significantly greater chances of delivering LBW babies than the age group above 20 years which corresponds with the findings in other studies $[55,56]$. The strong association between maternal age and birth weight found by our study is consistent with the findings of Vahdaninia et al.(2008) [57]. This could be due to the fact that, adolescent mothers are still in the process of biological growth and may not be physically and emotionally mature enough to know the importance of child bearing, self-care and good nutrition during pregnancy [46]. Other studies $[58,59]$ found a significant 
correlation between mother's antenatal care visits and birth weight which contradicts the findings of our study.

The association between birth weight and parity has been established by other studies $[41,60]$ and our findings are consistent with the findings of these. The results of our study showed a significant relationship between maternal occupation and infant birth weight. These findings are contrary to findings of other studies which found no association between maternal occupation and infant birth weight [61-64].

\section{Limitations}

Although this study offers some advantages such as the large sample size and quality of data, it also has important limitations. Other important variables that have been shown to affect birth weight, such as mother's weight gain during pregnancy, maternal history of disease, gestational age $[65,66]$, were not available in the secondary data used for this study. These factors and the high proportion of babies not weighed at birth due to deliveries outside health facilities might have provided additional information about the determinants of birth weight. The generalization of these findings beyond the study districts may be unlikely because the DHDSS covers only two districts.

\section{Conclusion}

This population based study reveals important information about the determinants of birth weight of babies born in southern rural Ghana. Maternal age, occupation, parity, socioeconomic status and infant's gender, appear to be significant determinants of birth weight.

Low birth weight is a significant public health problem and as multiple factors are associated with it, it requires a more holistic and multisectorial approach for its reduction. Interventions targeting high-risk women needs to be implemented to provide better health care services to all antenatal teenagers and women with high parity. Early registrations of pregnancy should be promoted so as to detect the presence of any high-risk factors as early as possible during the pregnancy. Health promotion in this regard should be targeted towards the high-risk women. Targeting social interventions to improve the socioeconomic status of women from poor households may help reduce the incidents of LBW. Further research in this area is needed to explore and explain the influence of other important variables on birth weight.

\section{Abbreviations}

ANC, antenatal care; CDC, Centres for Disease and Control; Cl, confidence intervals; DHDSS, Dodowa Health and Demographic Surveillance System; DHRC, Dodowa Health Research Centre; ELBW, extremely low birth weight; GDHS, Ghana Demographic Health Survey; HBW, high birth weight; LBW, low birth weight; LPG, liquefied petroleum gas; MDG, Millennium Development
Goal; MICS, Multiple Indicator Cluster Survey; NBW, normal birth weight; OR, odd ratio; PCA, principal component analysis; VLBW, very low birth weight

\section{Acknowledgements}

We acknowledge the hard work and commitment of the field and the data team of the Dodowa Health and Demographic Surveillance System. The authors are grateful to all those who read this manuscript for their comments and residents in the surveillance area for offering their time for interviews and consistently sharing their valuable personal information over the years. We thank INDEPTH Network for providing technical support to the DHDSS and the travel award to the corresponding author to present this paper at the INDEPTH SCIENTIFIC CONFERENCE 2015 in Addis Ababa.

\section{Funding}

The Dodowa Health and Demographic Surveillance System has no core funding. It is supported through on-going projects at the Dodowa Health Research Centre such as INDEPTH Effectvieness and Safety Studies (INESS) through the INDEPTH Network, Rectal Artesunate and Malaria Pneumonia study through WHO/TDR.

\section{Availability of data and materials}

The data supporting the findings in this paper is kept in an anonymous electronic archive at the Dodowa Health Research Centre. Due to the ethical policies of Dodowa Health Research Centre and participant confidentially, we are unable to make the dataset publically available.

\section{Authors' contributions \\ All authors have read and approved the manuscript. AK Manyeh: Participated in the conceptualisation, the study design, literature review, data extraction, data analysis, writing the results and discussion. VK: Participated in the conception and design, conducted the literature review and reviewed the manuscript. SN and GO: Participated in data extraction, statistical analysis, data interpretation and review. AA: Involved in conception, design, data interpretation and reviewed the manuscript. RAE: Conducted the literature review, writing the introductory section and reviewed the manuscript. DEA: Provided statistical support and reviewed the manuscript. MG: Participated in refining the initial research idea and critically reviewed the drafts.}

\section{Competing interests}

The authors declare that they have no competing interests.

\section{Consent for publication}

The manuscript does not include any individual persons data; hence consent to publish is not applicable.

\section{Ethics approval and consent to participate}

Data collection procedures and quality assurance of DHDSS was approved by the Ethical Committee of Ghana Health Service, the Institutional Review Board of Dodowa Health Research Centre (DHRC) and the INDEPTH Network. The use of data for this study was authorised by the management of DHRC and no identifying information was available to the researchers. The researchers briefed each respondent as well as their household heads about the HDSS data collection at the beginning of every update round. Participating individuals and households gave their consent prior to data collection and those who refused were excluded. To ensure confidentiality, names and other identifiers of the study participants were not included in the extracted data.

\section{Author details}

${ }^{1}$ Dodowa Health Research Centre, P. O. Box. DD1, Dodowa, Ghana. ${ }^{2}$ Shai-Osudoku District Hospital, Dodowa, Ghana. ${ }^{3}$ Ghana Health Services, Accra, Ghana.

Received: 23 June 2015 Accepted: 9 July 2016

Published online: 15 July 2016

\section{References}

1. World Health Organization. Regional consultation towards the development of a strategy for optimizing fetal growth and development. In. Cairo, Egypt: World Health Organization; 2005.

2. Abel EL. Prenatal exposure to cannabis: a critical review of effects on growth, development and behavior. Behav Neural Biol. 1980;29:137-56. 
3. Abrams B, Altman SL, Pickett KE. Pregnancy weight gain: still controversial. Am J Clin Nutr. 2000;71(5 Suppl):1233S-41.

4. Ghana Statistical Service. Ghana Multiple Indicator Cluster Survey with an Enhanced Malaria Module and Biomarker. In. Final Report. Accra, Ghana: Ghana Statistical Service; 2011.

5. Martin JA, Hamilton BE, Ventura SJ, Osterman MJ, Kirmeyer S, Mathews TJ, Wilson EC. Births: final data for 2009. Natl Vital Stat Rep. 2011;60(1):1-70.

6. Worl Health Organisation. Global nutrition targets 2025: low birth weight policy brief (WHO/NMH/NHD/14.5). Geneva: World Health; 2014.

7. March of Dimes, The Partnership for Maternal, Newborn \& Child Health, Save the Children, WHO. Born too soon: the global action report on preterm birth. Geneva: World Health Organization; 2012.

8. Kramer MS. Determinants of low birth weight: Methodological assessment and meta-analysis. Bull World Health Organ. 1987;65:663-737.

9. Sharma V, Katz J, Mullany LC, Khatry SK, LeClerq SC, Shrestha SR, Darmstadt GL, Tielsch JM. Young maternal age and the risk of mortality in Rural Nepal. Arch Pediatr Adolesc Med. 2008;162(9):828-35.

10. Khoshwood B. Risk of low birth weight associated with advanced maternal age among four ethnic four ethnic groups in United States. Matern Child Health J. 2005;9(1):3-9.

11. Simon DM, Vyas S, Prachand NG, David RJ, Collins Jr JW. Relation of maternal low birth weight to infant growth retardation and prematurity Matern Child Health J. 2006;10(4):321-7.

12. Rice F, Thapar A. Estimating the relative contributions of maternal genetic, paternal genetic intrauterine factors to offspring birth weight and head circumference. Early Hum Dev. 2010;86(7):425-32.

13. Mahanty C, Prasad R, Reddy S, Ghosh JK, Singh TB, Das BK. Maternal anthropometry as predictors of low birth weight. J Trop Pediatr. 2006;52(1):24-9.

14. Godfrey KM, Barker DJ. Maternal birthweight and diet in pregnancy in relation to the infant's thinness at birth. Br J Obstet Gynecol. 1997;104(6):663-7.

15. Brooks AA, Johnson MR, Steer PJ, Pawson ME, Abdalla HI. Birth weight: Nature or nurture? Early Hum Dev. 1995;42(1):29-35.

16. Stephenson T, Symonds ME. Maternal nutrition as a determinant of birth weight. Arch Dis Child Fetal Neonatal. 2002;Ed 86:F4-6.

17. Prentice AM, Whitehead RG, Watkinson M, Lamb WH, Cole TJ. Prenatal dietary supplementation of African women and birth-weight. Lancet. 1983;321(8323):489-92.

18. Magee $B D$, Hattis $D$, Kivel NM. Role of smoking in low with weight. J Reprod Med. 2004;49(1):23-7.

19. Yugantara RK, Anugya M, Pragati VC, Alka DG. Effect of prenatal exposure to kitchen fuel on birth weight. Indian J Community Med. 2013;38(4):212-6.

20. Tielsch JM, Katz J, Thulasiraj RD, Coles CL, Sheeladevi S, Yanik EL. Exposure to indoor biomass fuel and tobacco smoke and risk of adverse reproductive outcomes, mortality, respiratory morbidity and growth among newborn infants in south India. Int J Epidemiol. 2009:38:1351-63.

21. Washam C. Cooking with wood may fuel low birth weight: kitchen smoke puts babies at risk. Environ Health Perspect. 2008;116:A173.

22. Siddiqui AR, Gold EB, Yang X, Lee K, Brown KH, Bhutta ZA. Prenatal exposure to wood fuel smoke and low birth weight. Environ Health Perspect. 2008; 116:543-9.

23. Cramer JC. Racial and ethnic difference in birth weight: the role of income and financial assistance. Demography. 1995;32(2):231-47.

24. Kayode GA, Amoakoh-Coleman M, Agyepong IA, Ansah E, Grobbee DE, Klipstein-Grobusch K. (2014) Contextual risk Factors for low birth weight. A Multilevel Analysis. PLoS ONE 9(10):e109333. doi:10.1371/journal.pone.0109333.

25. Boerma JT, Weinstein Kl, Rutstein SO, Sommerfelt AE. Data on birth weight in developing countries: can surveys help? Bull World Health Organ. 1996;74(2):209-16

26. Spangler SA, Bloom S. Use of biomedical obstetric care in rural Tanzania: the role of social and material inequalities. Soc Sci Med. 2010;71(4):760-8.

27. Fotso JC, Ezeh A, Essendi H. Maternal health in resource-poor urban settings: How does women's autonomy influence the utilization of obstetric care services? Reprod Health. 2009;6(9):1-8.

28. Magadi M, Madise N, Diamond I. Factors associated with unfavourable birth outcomes in Kenya. J Biosoc Sci. 2001;33(2):199-225.

29. Onah HE, Ikeako LC, lloabachie GC. Factors associated with the use of maternal services in Enugu, Nigeria. Soc Sci Med. 2006;63(7):1870-8.

30. Wilcox AJ. On the importance - and the unimportance - of birthweight. Int J Epidemiol. 2001;30(6):1233-41.
31. Conde-Agudelo A, Rosas-Bermudez A, Kafury-Goeta AC. Birth spacing and risk of adverse perinatal outcomes. JAMA. 2006;295(15):1809-23.

32. Smith GC, Pell JP, Dobbie R. Interpregnancy interval and risk of preterm birth and neonatal death: Retrospective cohort study. Br Med J. 2003;327(7410):313.

33. Rawlings JS, Rawlings VB, Read JA. Prevalence of low birth weight and preterm delivery in relation to the interval between pregnancies among white and black women. N Engl J Med. 1995;332:69-74.

34. Zhu BP, Haines KM, Le T, McGrath-Miller K, Boulton ML. Effect of interval between pregnancies on perinatal outcomes among white and black women. Amer J Obst Gynecol. 2001;185(6):1403-10.

35. Zhu BP. Effects of interpregnancy interval on birth outcomes: Finding from three recent US studies. Int J Gynaecol Obstet. 2005;89(1):S25-33.

36. Ghana Statistical Service. Ghana Multiple Indicator Cluster Survey with an Enhanced Malaria Module and Biomarker. In. Final Report. Accra, Ghana: Ghana Statistical Service; 2006.

37. Awini E, Sarpong D, Adjei A, Manyeh KA, Amu A, Akweongo P, Adongo P, Kukula V, Odonkor G, Narh $S$, et al. Estimating cause of adult (15+ years) death using InterVA-4 in rural districts of southern Ghana. Glob Health Action. 2014;7.

38. Gyapong $M$, Sarpong $D$, Awini $E$, Manyeh KA, Tei $D$, Odonkor $G$ Agyepong IA, Mattah P, Wontuo P, Attaa-Pomaa M, et al. Health and Demographic Surveillance System profile: The Dodowa HDSS. Int J Epidemiol. 2013;42:1686-96.

39. Vyas S, Kumaranayake L. Constructing socio-economic status indices: how to use principal components analysis. Health Policy Plan. 2006;21(6):459-68.

40. Schulpis $\mathrm{KH}$, et al. The effect of nutritional habits on maternalneonatal zinc and magnesium levels in Greeks and Albanians. Eur E J Clin Nutr Metab. 2009;4(4):176-80.

41. Dowding VM. New assessment of the effect of birth order and socioeconomic class on birth weight. Br Med J. 1981;282:683-6.

42. Fosu MO, Munyakazi L, Nsowah-Nuamah NNN. Low birth weight and associated maternal factors in Ghana. J Biol Agric Healthcare. 2013;3:7.

43. Collins JW, Wambach J, David RJ, Rankin KM. Women's lifelong exposure to neighborhood poverty and low birth weight: a population-based study. Matern Child Health J. 2009:13(3):326-33.

44. Conley D, Bennett NG. Birth weight and income: Interactions across generations. J Health Soc Behav. 2001;42(4):450-65.

45. Janevic T, Stein CR, Savitz DA, Kaufman J, Mason SM, Herring AH. Neighborhood deprivation and adverse birth outcomes among diverse ethnic groups. Ann Epidemiol. 2010;20(6):445-51.

46. Shrivastava RS, Shrivastava PS. A longitudinal study of maternal and socioeconomic factors influencing neonatal birth weight in pregnant women attending an urban health centre. Saudi J Health Sci. 2013:2(2):87-92.

47. Fosu MO, Abdul-Rahaman I, Yekeen R. Maternal risk factors for low birth weight in a District Hospital in Ashanti Region of Ghana. Res Obstet Gynaecol. 2013;2(4):48-54.

48. Ubomba-Jaswa P, Ubomba-Jaswa SR. Correlates of low birth weight in Botswana. South African Journal of Demography. 1996;6(1):64-73.

49. Molly P, Jain PC, Prasad BG. A study of premature births at S.A.T. hospital Trivandrum. J Obstet Gynaecol India. 1970;20:66-67.

50. Koupilova I, Rahu K, Rahu M, Karro H, Leon DA. Social determinants of birthweight and length of gestation in Estonia during the transition to democracy. Int J Epidemiol. 2000;28:1088-95.

51. Khatun S, Rahman M. Socio-economic determinants of low birth weight in Bangladesh: a multivariate approach. Bangladesh Med Res Counc Bull. 2008;34(3):81-4.

52. Dougherty CRS, Jones AD. The determinants of birth weight. Am J Obstet Gynecol. 1982;144:190-200.

53. Kramer MS. Determinants of low birth weight: Methodological assessment and meta-analysis. Bull WHO. 1987;65:663-737.

54. Van-Roosmallen J. Birth weights in two rural hospitals in the United Republic of Tanzania. Bull WHO. 1988;66:653-8.

55. Ahmed FU, Das AM, Mostafa MG. Association of maternal biological factors with birth weight in Bangladesh. JOPSOM. 1994;13:52-7.

56. Eisner V, Brazie JV, Pratt MW, Hexter AC. The risk of low birth weight. AJPH. 1979:69:887-93.

57. Vahdaninia M, Tavafian SS, Montazeri A. Correlates of low birth weight in term pregnancies: a retrospective study from Iran. BMC Pregnancy Childbirth. 2008;8:12 
58. Negi KS, Kandpal SD, Kukreti M. Epidemiological factors affecting low birth weight. JK Sci. 2006;8(1):31-4

59. Joshi HS, Subba SH, Dabral SB, Dwivedi S, Kumar D, Singh S. Risk factors associated with low birth weight in newborns. Indian J Community Med. 2005;30:4.

60. Murphy JF, Dauncey M, Newcombe R, Garcia J, Elbourne D. Employment in pregnancy: prevalence, maternal characteristics, perinatal outcome. Lancet Global Health. 1984;1:1163-6.

61. Daniell WE, Vaughan TL, Millies BA. Pregnancy outcomes among female flight attendants. Aviat Space Environ Med. 1990;61:840-4.

62. Kanal E, Gillen J, Evans JA, Savitz DA, Shellock FG. Survey of reproductive health among female MR workers. Radiology. 1993;187:395-9.

63. Rantakallio P. The longitudinal study of the northern Finland birth cohort of 1966. Paediatr Perinat Epidemiol. 1988;2:59-88.

64. Nazari SY, Sharifah Zainiyah MS, Lye MS, Zalilah, Heidarzadeh M. Comparison of maternal characteristics in low birth weight and normal birth weight infants. East Mediterr Health J. 2013;19:9.

65. Ezeaka V, Eroha E, Egri-Okwaji WT. Maternal socio-biological factors associated with low birth weight in Lagos, Nigeria. Nig Q J Hosp Med. 2003;13:1-2.

66. Onyiriuka A. Low birthweight infants in twin gestation. Curr Pediatr Res. 2011:15(1):37-41.

Submit your next manuscript to BioMed Central and we will help you at every step:

- We accept pre-submission inquiries

- Our selector tool helps you to find the most relevant journal

- We provide round the clock customer support

- Convenient online submission

- Thorough peer review

- Inclusion in PubMed and all major indexing services

- Maximum visibility for your research

Submit your manuscript at www.biomedcentral.com/submit
Biomed Central 